SEABRA JÚNIOR, S.; PANTANO, S.C.; HIDALGO, A.H.; RANGEL, M.G.; CARDOSO, A.I.I. Avaliação do número e posição de frutos de melancia produzidos em ambiente protegido. Horticultura Brasileira, Brasília, v. 21, n. 4, p.708-711, outubro/dezembro 2003.

\title{
Avaliação do número e posição de frutos de melancia produzidos em ambiente protegido
}

\author{
Santino Seabra Júnior ${ }^{1,3}$; Sílvio C. Pantano ${ }^{1,3}$; Ari F. Hidalgo ${ }^{1,2}$; Maurício G. Rangel ${ }^{1}$; Antonio I.I. Cardoso ${ }^{1,4}$ \\ ${ }^{1}$ UNESP-FCA, DPV/Horticultura, C. Postal 237, 18603-970. Botucatu-SP; ${ }^{2}$ Prof. Assistente, Univ. do Amazonas. ${ }^{3}$ Doutorandos e bolsista \\ CAPES. ${ }^{4}$ Prof. Assistente Doutor FCA/UNESP; santinoseabra@fca.unesp.br.
}

\section{RESUMO}

Estudou-se a produção de melancia, cultivar New Kodama, avaliando 1 ou 2 frutos por planta fixados nos ramos entre o $8^{\circ}$ e $11^{\circ}$ nó e 1 ou 2 frutos por planta fixados nos ramos entre o $13^{\circ}$ e $16^{\circ}$ nó, no sistema tutorado em ambiente protegido. $\mathrm{O}$ experimento foi conduzido na UNESP, em Botucatu (SP), de outubro a dezembro de 2000. Avaliou-se a produção total de frutos por planta, peso médio de frutos e teor em sólidos solúveis totais ( ${ }^{\circ}$ brix). A produção foi menor $(2,04 \mathrm{~kg} / \mathrm{planta})$ quando manteve-se apenas um fruto fixado do $8^{\circ}$ ao $11^{\circ}$ nó, do que quando manteve-se dois frutos $(2,57 \mathrm{~kg} / \mathrm{planta})$, mas não houve diferença significativa quando manteve-se um ou dois frutos fixados do $13^{\circ}$ ao $16^{\circ}$ nó, produzindo cerca de $2 \mathrm{~kg}$ por planta. Observou-se também maior peso médio de frutos $(2,05 \mathrm{~kg} /$ fruto) e maior teor de sólidos solúveis totais $\left(8,78^{\circ}\right.$ brix $)$ quando mantidos apenas um fruto por planta e maior teor de sólidos solúveis totais $\left(8,21^{\circ}\right.$ brix $)$ nos frutos mantidos do $8^{\circ}$ ao $11^{\circ}$ nó.

Palavras-chave: Citrullus lanatus, poda, raleio, cultivo protegido, produção de frutos.

\begin{abstract}
Evaluation of the number and position of watermelon fruits cultivated in a greenhouse

The fruit production of watermelon, cultivar New Kodama, grown in two positions along the stem $\left(8^{\text {th }}-11^{\text {th }}\right.$ node and $13^{\text {th }}-16^{\text {th }}$ node), with one or two fruits per position was evaluated, under protected cultivation. The experiment was performed in Botucatu, São Paulo State, Brazil, from October to December, 2000. The total fruit production ( $\mathrm{kg} / \mathrm{plant})$, the average fruit weight ( $\mathrm{kg} /$ fruit) and the total soluble solids were evaluated. When only one fruit was allowed to grow between the $8^{\text {th }}$ and $11^{\text {th }}$ node, total fruit production was lower $(2,04 \mathrm{~kg} /$ plant $)$ than keeping two fruits $(2,57 \mathrm{~kg} /$ fruit $)$. However, the fruit production was similar $(2,0 \mathrm{~kg} / \mathrm{plant})$ to one or two fruits when they were allowed to grow between the $13^{\text {th }}$ and $16^{\text {th }}$ node. The average fruit weight $(2,05 \mathrm{~kg} /$ fruit $)$ and total soluble solids $\left(8,78^{\circ}\right.$ brix $)$ were higher in fruits grown from plants with only one fruit, than two fruits per plant. Total soluble solids were also higher in fruits grown from $8^{\text {th }}$ to $11^{\text {th }}\left(8,21^{\circ}\right.$ brix $)$ node position.
\end{abstract}

Keywords: Citrullus lanatus, pruning, rough-hewing, protected cultivation, fruit production.

(Recebido para publicação em 26 de maio de 2002 e aceito em 12 de agosto de 2003)

\begin{abstract}
$\mathrm{A}_{0}$ melancia (Citrullus lanatus) é ori ginária das regiões tropicais do continente africano, sendo cultura de grande importância na China, África, Índia e em outras regiões tropicais do mundo. No Brasil encontra condições climáticas favoráveis nos estados de Goiás e São Paulo, onde o cultivo desta olerícola se destaca. No estado de São Paulo a área cultivada cresceu 198\%, passando de 4.684 ha em 1990, para 9.283 ha em 1999, com produção passando de 123.902 para 236.471 toneladas (Trani et al., 1997; Camargo Filho \& Mazzei, 2000) sendo que a produtividade média variou de 25 a 32 t/ha (Camargo Filho \& Mazzei, 2000; Fernandes \& Capato, 2000).

Tradicionalmente a melancia é cultivada em campo aberto, conduzida no sistema rasteiro. Algumas cultivares diferenciadas pelo seu tamanho, coloração e ausência de sementes, buscam atender mercados diferenciados, exigen-
\end{abstract}

tes em qualidade e que ofereçam um bom retorno financeiro ao produtor. Para isso, são exigidas técnicas especiais de cultivo, como ambiente protegido, sistema de condução e podas adequadas, entre outras. Na literatura, são escassas as informações para o cultivo desta olerícola em ambiente protegido.

A condução das plantas e dos frutos é um trato cultural obrigatório para os produtores que buscam qualidade. Segundo Martins et al. (1998) a interação estabelecida entre planta, ambiente e práticas fitotécnicas, condicionam respostas fisiológicas e agronômicas, não só do ponto de vista quantitativo (rendimento), como também qualitativo (características organolépticas e nutricionais). Essas características, segundo os mesmos autores, são afetadas pelo manejo da água, cobertura do solo, práticas de tutoramento e poda, entre outros. A utilização de podas de ramos e folhas no manejo de plantas cultiva- das em estufas, é interessante para a melhor distribuição dos frutos na planta, e melhor controle fitossanitário (Gómez-Guilamón et al., 1997). O desbaste permite a obtenção de frutos maiores, indo de encontro ao gosto do consumidor brasileiro (Carvalho et al., 1988).

A posição do nó onde será conduzido o ramo produtivo é bastante discutida para a cultura do melão (Sin et al., 1991; Jaewook et al., 1994 e Maruyama et al., 2000). No entanto, para a cultura da melancia, não há relatos de trabalhos com esse intuito. A posição do fruto na planta pode afetar tanto a produtividade, como o seu tamanho, além do teor de sólidos solúveis totais. Maruyama et al. (2000) observaram menor produção quando os frutos de melão foram conduzidos nos ramos laterais do $5^{\circ}$ ao $8^{\circ}$ nó, quando comparado aos frutos fixados em ramos do $9^{\circ}$ ao $11^{\circ}$ nó. Quanto ao teor de sólidos solúveis totais em 
melão, Sin et al. (1991) observaram que frutos fixados do $8^{\circ}$ ao $10^{\circ}$ nó, apresentaram maior teor de sólidos solúveis que os fixados entre o $4^{\circ}$ e o $6^{\circ}$, e entre o $6^{\circ}$ e o $8^{\circ}$ nó, enquanto que Jaewook et al. (1994) observaram maior teor de sólidos solúveis nos frutos fixados no $9^{\circ}$ nó No entanto, Maruyama et al. (2000), não observaram influência da posição de fixação dos frutos sobre essa variável.

A melancia é uma espécie olerícola com alta potencialidade para seu cultivo em ambiente protegido, a fim de obter produtos diferenciados e de elevada qualidade. Assim, este trabalho teve por objetivo estudar a produção de melancia, cultivar New Kodama, de frutos pequenos, casca fina e polpa amarela, variando o número e a posição dos frutos na planta, conduzido no sistema tutorado em ambiente protegido.

\section{MATERIAL E MÉTODOS}

O experimento foi conduzido de setembro a dezembro de 2000, na UNESP em Botucatu, em estufa tipo arco, coberta com filme plástico transparente (75 micras), com aberturas laterais. As mudas da cultivar New Kodama (Takii) foram produzidas em bandejas de poliestireno expandido com 128 células, empregando o substrato de marca comercial Plantimax ${ }^{\circledR}$.

O transplante foi realizado em 04/ 10/00, 21 dias após a semeadura, para vasos com capacidade para 15 litros, contendo 1 planta por vaso. Os vasos foram preenchidos com substrato contendo $85 \%$ de solo, $5 \%$ de esterco de curral e $10 \%$ de casca de arroz carbonizada. O solo foi Latossolo VermelhoEscuro, álico e de textura média com as seguintes características químicas: M.O.= $18 \mathrm{~g} \mathrm{dm}^{3} ; \mathrm{pH}=3,8, \mathrm{P}=1,0 \mathrm{mg}$ $\mathrm{dm}^{-3} ; \mathrm{K}=0,1 \mathrm{mmol}_{\mathrm{c}} \mathrm{dm}^{-3} ; \mathrm{Ca}=3,0$ $\mathrm{mmol}_{\mathrm{c}} \mathrm{dm}^{-3} ; \mathrm{Mg}=1,0 \mathrm{mmol}_{\mathrm{c}} \mathrm{dm}^{-3} ; \mathrm{CTC}$ $=53 ; \mathrm{V}=7 \%$. Este foi tratado com Basamid $\circledast$, calcário dolomítico, para elevar a saturação de bases a $80 \%$, e realizou-se também a correção dos níveis de $\mathrm{P}$ e K a $200 \mathrm{mg} \mathrm{l}^{-1}$.

As adubações foram realizadas semanalmente, através de fertirrigação, com doses divididas em três épocas: desenvolvimento da planta (50 mg de N/vaso), até 40 dias após o transplante,

Tabela 1. Produção total de frutos (kg/planta) em função da interação entre número e posição de fixação do fruto em melancia 'New Kodama'. Botucatu, FCA/UNESP, 2000.

\begin{tabular}{lcc}
\hline \multirow{2}{*}{ Número de frutos } & \multicolumn{2}{c}{ Posição dos frutos * } \\
\cline { 2 - 3 } & $\mathbf{8}^{\circ}-\mathbf{1 1}^{\circ}$ & $\mathbf{1 3}^{\circ}-\mathbf{1 6}^{\circ}$ \\
\hline 1 & $2,04 \mathrm{bA}$ & $2,06 \mathrm{aA}$ \\
2 & $2,57 \mathrm{aA}$ & $2,07 \mathrm{aB}$ \\
\hline CV\% & 20,10 & 20,10 \\
\hline
\end{tabular}

* Médias seguidas de mesma letra, minúscula na coluna e maiúscula na linha, não diferem estatisticamente pelo teste de Tukey a $5 \%$ de probabilidade.

floração (50 mg de N/vaso, $50 \mathrm{mg}$ de P/ vaso e $50 \mathrm{mg}$ de $\mathrm{K} /$ vaso) de 41 aos 52 dias após o transplante e crescimento do fruto (50 $\mathrm{mg}$ de $\mathrm{N}$ e $50 \mathrm{mg}$ de $\mathrm{K} / \mathrm{vaso}$ ) até 75 dias após o transplante.

Os vasos foram dispostos em seis linhas, com espaçamento de $0,50 \mathrm{~m}$ entre plantas e 1,0 m entre linhas. As plantas foram tutoradas com fitilho plástico e os frutos foram envolvidos com sacos plásticos "tipo rede". Foi realizada capação da haste principal quando esta alcançou cerca de 1,8 m de altura. Realizou-se poda dos ramos laterais e desbaste dos frutos, acima e abaixo da posição desejada, deixando-se somente os ramos que poderiam originar os frutos referentes ao tratamento. Após o pegamento do fruto, realizou-se desbastes dos outros ramos que excediam ao tratamento. Os frutos foram fixados no $5^{\circ}$ nó dos ramos laterais, já que anteriormente a esta posição, somente observouse flores masculinas.

O delineamento experimental foi inteiramente casualizado, com 20 plantas por tratamento e cada planta considerada uma repetição. Foram estudados o número de frutos e a posição dos mesmos em ramos originados em duas posições da haste principal, sendo 1 ou 2 frutos mantidos no ramo do $8^{\circ}-11^{\circ}$ nó, e 1 ou 2 frutos mantidos no ramo do $13^{\circ}-16^{\circ}$ nó.

A colheita dos frutos foi realizada aproximadamente aos 35 dias após a antese, quando percebia-se que o fruto havia atingido seu tamanho máximo e estava perdendo o brilho característico (Corey et al., 1988). Foram avaliados a produção total, peso médio do fruto, comprimento, diâmetro e relação comprimento/diâmetro dos frutos e sólidos solúveis totais.

Para a análise estatística utilizou-se o programa Estat, comparando as mé- dias pelo teste de Tukey a 5\% de probabilidade.

\section{RESULTADOS E DISCUSSÃO}

Ocorreu interação entre o número e a posição dos frutos para a característica produção total. Quando foi conduzido um fruto por planta na posição mais baixa ( $8^{\circ}$ ao $11^{\circ}$ nó), obteve-se menor produtividade do que com plantas conduzidas com dois frutos na mesma posição (Tabela 1). Entretanto, nas plantas em que os frutos foram conduzidos entre o $13^{\circ}$ ao $16^{\circ}$ nó, não houve diferença na produção total com um ou dois frutos. Observa-se, também, que plantas conduzidas com dois frutos apresentaram maior produção na posição baixeira ( $8^{\circ}$ ao $11^{\circ}$ nó), do que plantas com dois frutos conduzidos entre o $13^{\circ}$ e o $16^{\circ}$ nó. Entretanto, quando deixouse um fruto por planta, a posição não interferiu na produtividade (Tabela 1).

Estes resultados são contrastantes com os obtidos por Maruyama et al. (2000) no cultivo de melão, onde plantas em que os frutos foram fixados do $5^{\circ}$ ao $8^{\circ}$ nó, apresentaram uma produção cinco vezes menor do que plantas em que os frutos foram fixados do $9^{\circ}$ ao $11^{\circ}$ e do $12^{\circ}$ ao $15^{\circ}$ nó. Frutos fixados em posição próxima à base da planta podem comprometer o desenvolvimento vegetativo da mesma e, consequentemente, a produção total. Se a planta tiver uma pequena área foliar no momento em que o(s) fruto(s) for(em) fixado(s), este(s) exerce(m) forte competição pelos fotoassimilados e nutrientes, por ser(em) um dreno muito forte e a planta reduz substancialmente o seu desenvolvimento vegetativo, conforme relatado por Marcellis (1991), na cultura do pepino. Entretanto, no pre- 
Tabela 2. Peso médio, comprimento (C), diâmetro (D), relação comprimento/diâmetro (C/D) e teor de sólidos solúveis totais (SST) de frutos em função do número e posição de fixação dos frutos em melancia 'New Kodama'. Botucatu, FCA/UNESP, 2000.

\begin{tabular}{|c|c|c|c|c|c|}
\hline $\begin{array}{c}\text { Números de } \\
\text { frutos }\end{array}$ & Peso médio (kg) & $C(\mathrm{~cm})$ & $D(\mathrm{~cm})$ & C/D & SST ( ${ }^{\circ}$ Brix) \\
\hline 1 & $2,05 a$ & $16,95 \mathrm{a}$ & $15,45 \mathrm{a}$ & $1,09 a$ & $8,78 a$ \\
\hline 2 & $1,16 \mathrm{~b}$ & $12,98 b$ & $12,41 b$ & $1,05 b$ & $6,68 \mathrm{~b}$ \\
\hline \multicolumn{6}{|l|}{$\begin{array}{l}\text { Posição dos } \\
\text { frutos }\end{array}$} \\
\hline $8^{\circ}-11^{\circ}$ & $1,66 \mathrm{a}$ & $15,41 \mathrm{a}$ & $14,12 \mathrm{a}$ & $1,1 \mathrm{a}$ & $8,21 \mathrm{a}$ \\
\hline $13^{\circ}-16^{\circ}$ & $1,57 \mathrm{a}$ & $14,51 \mathrm{~b}$ & $13,74 a$ & $1,05 \mathrm{~b}$ & $7,25 \mathrm{~b}$ \\
\hline$\overline{\mathrm{CV} \%}$ & 20,74 & 8,03 & 7,73 & 4,29 & 13,28 \\
\hline
\end{tabular}

* Médias seguidas pela mesma letra na coluna, não diferem estatisticamente pelo teste de Tukey a 5\% de probabilidade.

sente ensaio o tratamento com maior produção foi aquele com dois frutos fixados em posição baixeira $\left(8^{\circ}\right.$ ao $11^{\circ}$ nó), pois as plantas estavam bem desenvolvidas, com brotações laterais contendo 5 folhas verdadeiras. Brandão Filho \& Vasconcellos (1998), recomendam, para a cultura do melão, deixar entre um e dois frutos por planta em hastes secundárias, contendo duas folhas, podandose as demais, de forma que as folhas que permanecem sirvam como fonte de assimilados para o(s) fruto(s). Para a melancia 'New Kodama' constatou-se que a poda deve ser realizada a partir da quinta folha, local onde normalmente surge a primeira flor feminina.

Nas condições experimentais, não houve interação entre o número e a posição dos frutos para as caraterísticas peso médio, comprimento, diâmetro, relação comprimento/diâmetro e sólidos solúveis totais. O maior peso médio foi obtido com plantas cultivadas com apenas um fruto (Tabela 2). Resultados semelhantes foram obtidos por Tanaka \& Fujita (1974) em tomateiro: verificaram que quanto menor o número de frutos (dreno), maior o tamanho dos mesmos, crescendo até seu limite em termos de potencial genético, não compensando a perda na produção total com o desbaste dos mesmos.

No comprimento e no diâmetro dos frutos, observou-se a mesma tendência do peso médio, ou seja, obteve-se frutos com maiores dimensões quando foi deixado apenas um fruto por planta. Entretanto, pode-se observar por meio da relação comprimento/diâmetro, que o comprimento influenciou mais no peso médio dos frutos, pois os menos ficaram menos arredondados em plantas com apenas um fruto (Tabela 2).

A recomendação de fazer o desbaste para aumentar o tamanho dos frutos de melancia é indicada por Carvalho et al. (1988), pois o consumidor brasileiro geralmente prefere frutos maiores. Esta preferência pode estar relacionada com o teor de sólidos solúveis totais, pois Araújo Neto et al. (2000) ao avaliarem a qualidade de melancia 'Crimson Sweet' comercializadas em Mossoró, observaram que frutos de maior tamanho apresentavam-se mais doces. Apesar da melancia 'New Kodama' ser um produto diferenciado, pode ser interessante deixar apenas um fruto por planta, desde que o maior peso dos frutos proporcione um aumento substancial de preço. Caso contrário, é mais interessante deixar dois frutos por planta, pois aumenta-se a produção total.

Além do maior peso médio, com apenas um fruto por planta, obteve-se frutos com maior teor de sólidos solúveis totais (Tabela 2). Monteiro \& Mexia (1988), observaram esta mesma tendência para a cultura do meloeiro, por haver maior disponibilidade de área foliar por fruto. Este pode ser um fator primordial na diferenciação do produto junto ao consumidor, principalmente pela preferência deste por frutos maiores e mais doces.

Quanto à posição dos frutos nas plantas, observou-se que a posição em que foram conduzidos não influenciou o peso e o diâmetro destes (Tabela 2). Entretanto, o comprimento e a relação comprimento/diâmetro foram influencia- dos pela posição em que os frutos foram fixados, verificando que na posição mais baixa $\left(8^{\circ}\right.$ ao $\left.11^{\circ}\right)$, os frutos apresentaramse mais compridos (Tabela 2).

O teor de sólidos solúveis totais foi influenciado pela posição dos frutos, verificando-se que frutos fixados na posição mais baixa $\left(8^{\circ}\right.$ ao $\left.11^{\circ}\right)$ apresentaram cerca de $13 \%$ a mais de sólidos solúveis totais que os frutos conduzidos no $13^{\circ}$ ao $16^{\circ}$ nó. Estes resultados seguem os mesmos padrões de recomendação apresentados por Brandão Filho \& Vasconcellos (1998), para a cultura do melão. Este acúmulo pode estar relacionado com a espécie e com o híbrido utilizado. Sin et al. (1991) encontraram, em melão cultivar HouseEuncheon, maior teor de sólidos solúveis na posição do $8^{\circ}$ ao $10^{\circ}$ nó quando comparado com posições mais baixas $\left(4^{\circ}\right.$ ao $6^{\circ}$ e $6^{\circ}$ ao $8^{\circ}$ nó). Porém, no híbrido Keumssaragi não observaram diferença entre as posições de fixação dos frutos.

Com base nestes resultados, recomenda-se que quando o objetivo for melhorar a qualidade dos frutos, devese conduzir as plantas com um fruto localizado em ramos entre o $8^{\circ}$ e o $11^{\circ}$ nós, obtendo frutos maiores e com maior teor de sólidos solúveis totais. Porém, quando o objetivo for aumentar a produção total, recomenda-se deixar dois frutos por planta fixados na posição mais baixa (ramos entre o $8^{\circ}$ e o $11^{\circ}$ nó).

\section{LITERATURA CITADA}

ARAÚJO NETO, S.E., HAFLE, O.M., GURGEL, F.L., MENEZES, J.B., SILVA, G.G. Qualidade da melancia 'Crimson Sweet', comercializada em Mossoró-RN. Horticultura Brasileira, v. 18, p. 850-852, 2000. 
BRANDÃO FILHO, J.U.T.; VASCONCELLOS, M.A.S. A cultura do meloeiro. In: GOTO, R., TIVELLI, S.W. Produção de hortaliças em ambiente protegido: condições subtropicais. São Paulo: Ed. Unesp. p. 161-93, 1998.

CAMARGO FILHO, W.P.; MAZZEI, A.R. Abastecimento de legumes: tendência de preços. Informações Econômicas. v. 30, n. 10, p. 35-49, 2000. CARVALHO, N.M.; CASTELANI, P.D., VIERA, R.D. Produção de sementes de melancia. Jaboticabal; FCAV/UNESP, 1988, 30 p.

COREY, K.A.; SCHLIMME, D.V., CHANEY, N.A. Changes in epicuticular wax on watermelon fruits during ripening. HortScience, v. 23, n. 4, p. 730-731, 1988.

FERNANDES, F.M.; CAPATO, F. Adubação da cultura da melancia: I - fontes e níveis de adubo orgânico, com e sem aplicação foliar de boro e zinco. Horticultura Brasileira, Brasília, v. 18, p. 845-846, 2000.

GÓMEZ-GUILAMÓN, M.L.; FLORES, R.C.; GONZÁLEZ-FERNANDÉZ, J.J. El melon in invernadero. In: VALLESPIR, A.N. Melones. Barcelona: Ediciones de Horticultura, p. 67-77, 1997.
JAEWOOK, L.; HANCHUL, R.; CHANGJAE, Y.; KYUCHIL, K.; HWAMO, Y.; LIM, J.W.; RHEE, H.C.; YU, C.J. Effect of fruiting number, fruiting position and training methods on fruit characteristic and quality in melon (cv. Sul Hyang melon). Journal of Agricultural Science, v. 36, n. 2, p. 413-417, 1994.

MARCELIS, L.F.M. Effects of sink demand of photosynthesis in Cucumber. Journal of experimental botany, v. 42, n. 244, p. 1387-92, 1991. MARTINS, S.R.; PEIL, R.M.; SCHWENGBER, J.E.; ASSIS, F.N.; MENDEZ, M.E.G. Produção de melão em função de diferentes sistemas de condução de plantas em ambiente protegido. Horticultura brasileira, Brasília, v. 16, n. 1, p. 2430, 1998.

MONTEIRO, A.A.; MEXIA, J.T. Influência da poda e do número de frutos por planta na qualidade dos frutos e produtividade do melão. Horticultura Brasileira, Brasília, v. 6, n. 1, p. 912, 1988.
MARUYAMA, W.I.; BRAZ, L.T.; CECÍLIO FILHO, A.B. Condução de melão rendilhado sob cultivo protegido. Horticultura Brasileira, Brasília, v. 18, n. 3, p. 175-9, 2000.

SIN, G.Y.; HEONG, C.S.; YOO, K.C. Effects of temperature, ligth intensity and fruit setting position on sugar accumulation and fermentation in oriental melon. Journal of Korean Society for Horticultural Science, v. 32, n.4, p. 440-446, 1991. TANAKA, A.; FUJITA, F. Nutrio-physiological studies on the tomato plant IV. Source-sink relationship and structure of the source-sink unit. Soil Science Plant Nutrition, v. 20, n. 3, p. 305315, 1974.

TRANI, P.E.; GROPPO, G.A.; SILVA, M.C.P.; BURKE, T.J. Diagnóstico sobre a produção de hortaliças no estado de São Paulo. Horticultura Brasileira, v. 15, n. 1, p. 19-24, 1997. 